\title{
Cr isotopic search for a core component in basalts from the Ontong Java Plateau and Samoan Ocean Islands.
}

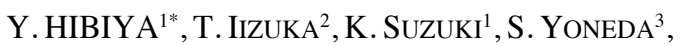

${ }^{1}$ Japan Agency for Marine-Earth Science and Technology, Kanagawa, 237-0061, Japan. (hibiyuki@ jamstec.go.jp)

${ }^{2}$ The University of Tokyo, Tokyo 113-0033, Japan.

${ }^{3}$ National Museum of Nature and Science, Ibaraki 305-0005, Japan.

Some volcanic rocks from large igneous provinces (LIPs) and from ocean islands (OIBs) are characterized by ${ }^{182} \mathrm{~W}$ deficits that are well resolved from the ambient upper mantle $[1,2]$. This negative ${ }^{182} \mathrm{~W}$ signature has recently been proposed to originate from the outer core [3-5]. If so, the ${ }^{182} \mathrm{~W}$ anomaly may be accompanied by deficits of ${ }^{53} \mathrm{Cr}$, a decay product of a short-lived radionuclide ${ }^{53} \mathrm{Mn}$, because $\mathrm{Cr}$ is more siderophile than Mn especially at high temperature $[6$, 7]. However, the $\mathrm{Cr}$ isotope compositions of LIPs and OIBs are still poorly known. Here, we report investigation of mass independent $\mathrm{Cr}$ isotopic variation in basaltic rocks from the Ontong Java Plateau (OJP) and Samoan OIBs. The chemical separation and purification of $\mathrm{Cr}$ from samples were made following the procedure described by [8]. We have measured $\mathrm{Cr}$ stable isotope compositions of the samples processed through the separation scheme by thermal ionization mass spectrometry (TIMS). The $\mathrm{Cr}$ isotope analyses yielded $\varepsilon^{53} \mathrm{Cr}$ $=0.03 \pm 0.05, \varepsilon^{54} \mathrm{Cr}=0.02 \pm 0.10$ (2SE) for the OJP basalts, and $\varepsilon^{53} \mathrm{Cr}=0.03 \pm 0.05, \varepsilon^{54} \mathrm{Cr}=-0.03 \pm 0.11 \sim 0.05 \pm 0.11$ for the Samoan basalts. The results for both the OJP and Samoan basalts reveal that there is no resolvable ${ }^{53,}{ }^{54} \mathrm{Cr}$ anomalies in their source mantle. Our results suggest that there's no systematical contribution to $\mathrm{Cr}$ isotope signatures in the source of OJP and Samoan islands from materials with anomalous $\mathrm{Cr}$ isotope compositions. This implies that, unlike $\mathrm{Hf} / \mathrm{W}$, the fractionation of $\mathrm{Mn} / \mathrm{Cr}$ was restricted during coremantle differentiation, or that the $\mathrm{W}$ isotope variations are not due to core-mantle interaction.

[1] Mundl et al. (2017) Science 356 66-69, [2] Willbold et al. (2011) Nature 477 195-199, [3] Rizo et al. (2019) GRL 11 611, [4] Mundl et al. (2017) Science 356 66-69. [5] Kleine et al (2009) GCA 73 5150-5188, [6] McDonough et al. (2003) ToG2 $568559-575$, [7] Chabot and Agee (2003) GCA 67, 2077-2091, [8] Hibiya et al. (2019) GGR 43 133-145. 